Chem Commun (Camb). 2017 September 28; 53(78): 10824-10826. doi:10.1039/c7cc06409h.

\title{
Polymer nanodiscs and macro-nanodiscs of a varying lipid composition
}

\author{
Venkata Sudheer Kumar Ramadugu, Giacomo Di Mauro, Thirupathi Ravula, and \\ Ayyalusamy Ramamoorthy \\ Biophysics Program and Department of Chemistry, The University of Michigan, Ann Arbor, MI \\ 48109-1055, USA
}

\begin{abstract}
Polymer lipid nanodiscs have enabled some exciting structural biology and nanobiotechnology applications. The use of a small molecular weight polymer (SMA-EA) has been demonstrated to dramatically increase the size of nanodiscs (upto $\sim 60 \mathrm{~nm}$ diameter). Here, we report the first demonstration of the formation of macro-nanodiscs for a variety of lipids, and solid-state NMR experiments utilizing their magnetic-alignement properties.
\end{abstract}

\section{Graphical Abstract}

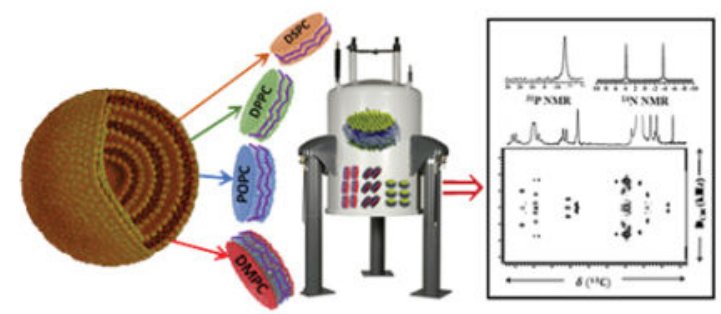

\begin{abstract}
Lipid nanodiscs are considered to be the most desirable membrane mimetics for structural and functional studies on membrane proteins. ${ }^{1-3}$ Studies have demonstrated successful applications of lipid bilayer nanodiscs formed by scaffold protein, peptide or polymer. ${ }^{4-7}$ Recent studies reported various physicochemical properties of lipid bilayers encapuslated by a polymer in naodiscs. ${ }^{8-15}$ Because of the inexpensive production and high stability, polymer based nanodiscs are increasingly utilized in the extraction and structural studies of membrane proteins ${ }^{16-18}$, and also in nanobiotechnological applications including drug delivery ${ }^{19,20}$. In particular, a recently introduced small molecular weight SMA-EA polymer dramatically enhanced the previously reported maximum nanodisc size limit of $\sim 20 \mathrm{~nm}$ to $\sim 60 \mathrm{~nm}$ diameter and also exhibited better stability to low $\mathrm{pH}$ and high concentrations of divalent metal ions. ${ }^{21}$ One of the most unique properties of the large nanodiscs (called as "macro-nanodiscs") is their magnetic-alignment, which opened the doors for static solidstate NMR applications on polymer nanodiscs for structural studies of membrane
\end{abstract}

Electronic Supplementary Information (ESI) available: Sample preparation and additional experimental results are available in ESI. See DOI: $10.1039 / \mathrm{x} 0 \mathrm{xx} 00000 \mathrm{x}$ 
proteins. ${ }^{21}$ In this study, we demonstrate the nanodiscs and macro-nanodiscs formation by SMA-EA polymer for different types of lipids including thinner and thicker lipid bilayers, and also the applications of solid-state NMR to fully characterize the structure and dynamics of lipids in macro-nanodiscs.

While polymer nanodiscs are becoming highly valuable membrane mimetics for various applications, most of the reported studies commonly use a simple DMPC lipid as the ability to reconstitute different types of lipids depends on various factors including the charge of the polymer and how well it can encapsulate the thinner and thicker lipid bilayers. As shown in Figure 1, the dynamic light scattering (DLS) profiles and static ${ }^{31} \mathrm{P}$ NMR spectra confirm the lipid macro-nanodiscs formation by the SMA-EA polymer for DPPC, POPC, DMPC, and DSPC. The DLS profiles in Figure 1D show the size distribution of nanodiscs formed, indicating that the SMA-EA polymer is able to form stable macro-nanodiscs for different types of lipids. Static ${ }^{31} \mathrm{P}$ solid-state NMR spectra of lipids in MLVs show a CSA powder pattern with a frequency span of $\sim 40 \mathrm{ppm}$ (Figure 1E). On the other hand, the addition of polymer solubilizes MLVs to form fast tumbling small nanodiscs to result in isotropic peaks as shown in the Figures 1E and S2 for different types of lipids. These NMR results provide additional confirmation for the formation of nanodiscs. While the nanodiscs can be easily characterized by TEM images (Figure 1C) and DLS (Figure 1D), and solution NMR can be used to study the nanodiscs as well as the reconstituted proteins at high-resolution, in this study we focused on demonstrating the unique magnetic-alignment properties of macronanodiscs by using solid-state NMR experiments (Figures 2, 3 and S3); aligned lipid bilayers of macro-nanodiscs can be used for high-resolution structure and dynamics studies on membrane proteins by using well-established solid-state NMR experiments.

Macro-nanodiscs were prepared as explained in the supporting information by simply changing the lipid:polymer ratio. The observed narrow ${ }^{31} \mathrm{P}(\sim-18 \mathrm{ppm})$ and ${ }^{14} \mathrm{~N}(\sim 8 \mathrm{kHz}$ quadrupole splitting) NMR spectral lines confirm the spontaneous magnetic-alignment of macro-nanodiscs with the DMPC bilayer normal perpendicular to the external magnetic field of the spectrometer as shown in Figure 2. Since the motionally-averaged ${ }^{31} \mathrm{P}$ CSA span for large unilamellar vesicles is $\sim 38 \mathrm{ppm}$ (from 20 to $-18 \mathrm{ppm}$, with an isotropic peak is at $\sim 2.9$ ppm with respect to that of $100 \%$ phosphoric acid at $0 \mathrm{ppm}$ ), the perpendicular orientation of the lipid bilayer normal resulted in a narrow peak at the perpendicular edge of the CSA ( $-18 \mathrm{ppm})$. Similarly, the motionally-averaged ${ }^{14} \mathrm{~N}$ quadrupolar coupling for the neartetrahedral symmetric choline group exhibits $\sim 8 \mathrm{kHz}$ splitting for the perpendicular orientation of the bilayer normal. On the other hand, the observed peak positions changed, for both for ${ }^{31} \mathrm{P}$ and ${ }^{14} \mathrm{~N}$, with the addition of $\mathrm{YbCl}_{3}$ to macro-nanodiscs indicating that the interaction of lanthanide ions with lipids altered the magnetic susceptibility to result in a change in the orientation of the macro-nanodiscs. ${ }^{22}$ The ${ }^{31} \mathrm{P}$ peak shifted to $\sim 20 \mathrm{ppm}$ and the ${ }^{14} \mathrm{~N}$ quadruple splitting increased to $\sim 16 \mathrm{kHz}$ when the bilayer normal is aligned parallel to the magnetic field axis. Experiments performed by varying $\left[\mathrm{YbCl}_{3}\right]$ revealed the lanthanide ion concentration dependent tilt of macro-nanodiscs as shown in Figure 2; it is remarkable that the bilayer normal can also be aligned at the magic angle which results in an isotropic peak. 
As shown in Figure 3, solid-state NMR spectra demonstrate that the SMA-EA polymer macro-nanodiscs containing other types of lipids (POPC, DPPC or DSPC) can also be aligned and flipped using $\mathrm{YbCl}_{3}$ (also see Figures S3 and S4). While the trend in the changes observed for ${ }^{31} \mathrm{P}$ chemical shift and ${ }^{14} \mathrm{~N}$ quadrupole splitting with the addition of lanthanide ions are similar, there are some minor differences can be seen between the spectra obtained from different lipid macro-nanodiscs. This may be attributed to the differences in the motionally-averaged ${ }^{31} \mathrm{P} \mathrm{CSA}$ and ${ }^{14} \mathrm{~N}$ quadrupole coupling powder pattern spectra for these lipids.

The magnetic-alignment of macro-nanodiscs enable the application of more sophisticated solid-state NMR. One of the most commonly used solid-state NMR experiment is 2D separated-local-field (SLF) NMR. The heteronuclear dipolar couplings measured for chemically different groups from an aligned molecule by 2D SLF experiment can be converted to measure the degree of disorder or order of chemical groups or bonds as a function of temperature, hydration, ions, $\mathrm{pH}$, or concentration of a ligand, peptide, or drug. To demonstrate this feasibility, 2D PELF (proton evolved local field) ${ }^{23-25}$ experiments were carried out on magnetically-aligned SMA-EA macro-nanodiscs of DMPC (Figure 4) and DPPC (Figure S5). First of all, as shown in Figures 4 (for DMPC) and S5 (for DPPC), the natural-abundance $1 \mathrm{D}{ }^{13} \mathrm{C}$ spectra under static conditions exhibit well-resolved spectral lines with excellent signal-to-noise ratio as that observed for well-aligned bicelles. The high sensitivity and high resolution observed in 1D spectra enabled an easy implementation of 2D experiments, even though the sample is not labeled with ${ }^{13} \mathrm{C}$ isotope. The $2 \mathrm{D}$ PELF spectrum displays excellent resolution in both dimensions and allows for the extraction of anisotropic ${ }^{13} \mathrm{C}$ chemical shift as well as ${ }^{1} \mathrm{H}-{ }^{13} \mathrm{C}$ dipolar coupling for each resolved ${ }^{13} \mathrm{C}$ peak of the lipid. The ${ }^{1} \mathrm{H}_{-}{ }^{13} \mathrm{C}$ dipolar coupling slices extracted from the 2D PELF spectrum also exhibit well resolved multiplet patterns for direct measurement of ${ }^{1} \mathrm{H}-{ }^{13} \mathrm{C}$ dipolar couplings. The ${ }^{1} \mathrm{H}_{-}{ }^{13} \mathrm{C}$ dipolar couplings measured from the $2 \mathrm{D}$ spectra are converted into order parameters for the $\mathrm{C}-\mathrm{H}$ bonds of the lipid (Table $\mathrm{S} 1$ ).

In conclusion, we have successfully demonstrated the polymer nanodiscs formation for a variety of lipid compositions such as DMPC, DPPC, DSPC, POPC, and POPC:POPG, and, for the first time, the formation of macro-nanodiscs and their magnetic alignment properties. We expect that these results to significantly expand the applications of nanodiscs by enabling the use of near-native lipid composition and to investigate the role of lipid composition on folding, aggregation and function of a variety of proteins including ionchannels, protein-protein complexes and amyloid proteins. The ability to tune the flip of macro-nanodiscs gradually from perpendicular to parallel orientation of the lipid bilayer normal accomplished by titrating with lanthanide ions will be useful in the structural studies of membrane proteins by solid-state NMR spectroscopy. We have also demonstrated the measurement of order/disorder of lipid acyl chains by the separated-local-field (SLF) NMR experiments. In addition to completely characterizing the formation of polymer nanodiscs and macro-nanodiscs, the reported results show the feasibilities of determining the structure and dynamics of the head group and acyl chain regions of lipids for studies on peptide/ protein interactions with membrane. 


\section{Supplementary Material}

Refer to Web version on PubMed Central for supplementary material.

\section{Acknowledgments}

This study was supported by NIH (GM084018 and AG048934 to A.R.).

\section{References}

1. Denisov IG, Sligar SG. Nat Struct Mol Biol. 2016; 23:481-486. [PubMed: 27273631]

2. Denisov IG, Sligar SG. Chem Rev. 2017; 117:4669-4713. [PubMed: 28177242]

3. Nasr ML, Baptista D, Strauss M, Sun ZYJ, Grigoriu S, Huser S, Pluckthun A, Hagn F, Walz T, Hogle JM, Wagner G. Nat Meth. 2017; 14:49-52.

4. Zhang M, Huang R, Ackermann R, Im SC, Waskell L, Schwendeman A, Ramamoorthy A. Angewandte Chemie International Edition. 2016; 55(14):4497-4499. [PubMed: 26924779]

5. Oluwole A, Danielczak B, Meister A, Babalola J, Vargas C, Keller S. Angewandte Chemie International Edition. 2017; 56:1919-1924. [PubMed: 28079955]

6. Park SH, Berkamp S, Cook GA, Chan MK, Viadiu H, Opella SJ. Biochemistry. 2011; 50:89838985. [PubMed: 21936505]

7. Dörr JM, Koorengevel MC, Schäfer M, Prokofyev AV, Scheidelaar S, van der Cruijsen EAW, Dafforn TR, Baldus M, Killian JA. Proc Natl Acad Sci USA. 2014; 111:18607-18612. [PubMed: 25512535]

8. Cuevas R, Arenas, Danielczak B, Martel A, Porcar L, Breyton C, Ebel C, Keller S. Sci Rep. 2017; 7:45875. [PubMed: 28378790]

9. Cuevas R, Arenas, Klingler J, Vargas C, Keller S. Nanoscale. 2016; 8:15016-15026. [PubMed: 27471007]

10. Scheidelaar S, Koorengevel Martijn C, Pardo Juan D, Meeldijk Johannes D, Breukink E, Killian JA. Biophys J. 2015; 108:279-290. [PubMed: 25606677]

11. Dominguez JJ, Pardo, Dörr JM, Iyer A, Cox RC, Scheidelaar S, Koorengevel MC, Subramaniam V, Killian JA. Eur Biophys J. 2017; 46:91-101. [PubMed: 27815573]

12. Zhang R, Sahu ID, Liu L, Osatuke A, Comer RG, Dabney-Smith C, Lorigan GA. BBA Biomembranes. 2015; 1848:329-333. [PubMed: 24853657]

13. Craig AF, Clark EE, Sahu ID, Zhang R, Frantz ND, Al-Abdul-Wahid MS, Dabney-Smith C, Konkolewicz D, Lorigan GA. Biochimica et Biophysica Acta (BBA) - Biomembranes. 2016; 1858:2931-2939. [PubMed: 27539205]

14. Martinez D, Decossas M, Kowal J, Frey L, Stahlberg H, Dufourc EJ, Riek R, Habenstein B, Bibow S, Loquet A. Chemphyschem. 2017; n/a-n/a. doi: 10.1002/cphc.201700450

15. Orwick-Rydmark M, Lovett JE, Graziadei A, Lindholm L, Hicks MR, Watts A. Nano Letters. 2012; 12(9):4687-4692. [PubMed: 22827450]

16. Lee SC, Knowles TJ, Postis VLG, Jamshad M, Parslow RA, Lin Y-p, Goldman A, Sridhar P, Overduin M, Muench SP, Dafforn TR. Nat Protocols. 2016; 11:1149-1162. [PubMed: 27254461]

17. Hagn F, Etzkorn M, Raschle T, Wagner G. J Am Chem Soc. 135; 2013:1919-1925.

18. Bersch B, Dörr JM, Hessel A, Killian JA, Schanda P. Angewandte Chemie International Edition. 2017; 56:2508-2512. [PubMed: 28128538]

19. Ladokhin A. Toxins. 2013; 5:1362. [PubMed: 23925141]

20. Kuhlbrandt W. Nat Rev Mol Cell Biol. 2004; 5:282-295. [PubMed: 15071553]

21. Ravula T, Ramadugu S, Di Mauro G, Ramamoorthy A. Angewandte Chemie International Edition. 2017; doi: 10.1002/anie.201705569

22. Prosser RS, Hwang JS, Vold RR. Biophys J. 1998; 74:2405-2418. [PubMed: 9591667]

23. Caravatti P, Bodenhausen G, Ernst RR. Chem Phys Lett. 1982; 89:363-367.

24. Schmidt-Rohr K, Nanz D, Emsley L, Pines A. J Phys Chem. 1994; 98:6668-6670. 
25. Xu J, Smith PE, Soong R, Ramamoorthy A. L Phys Chem B. 2011; 115:4863-71. 


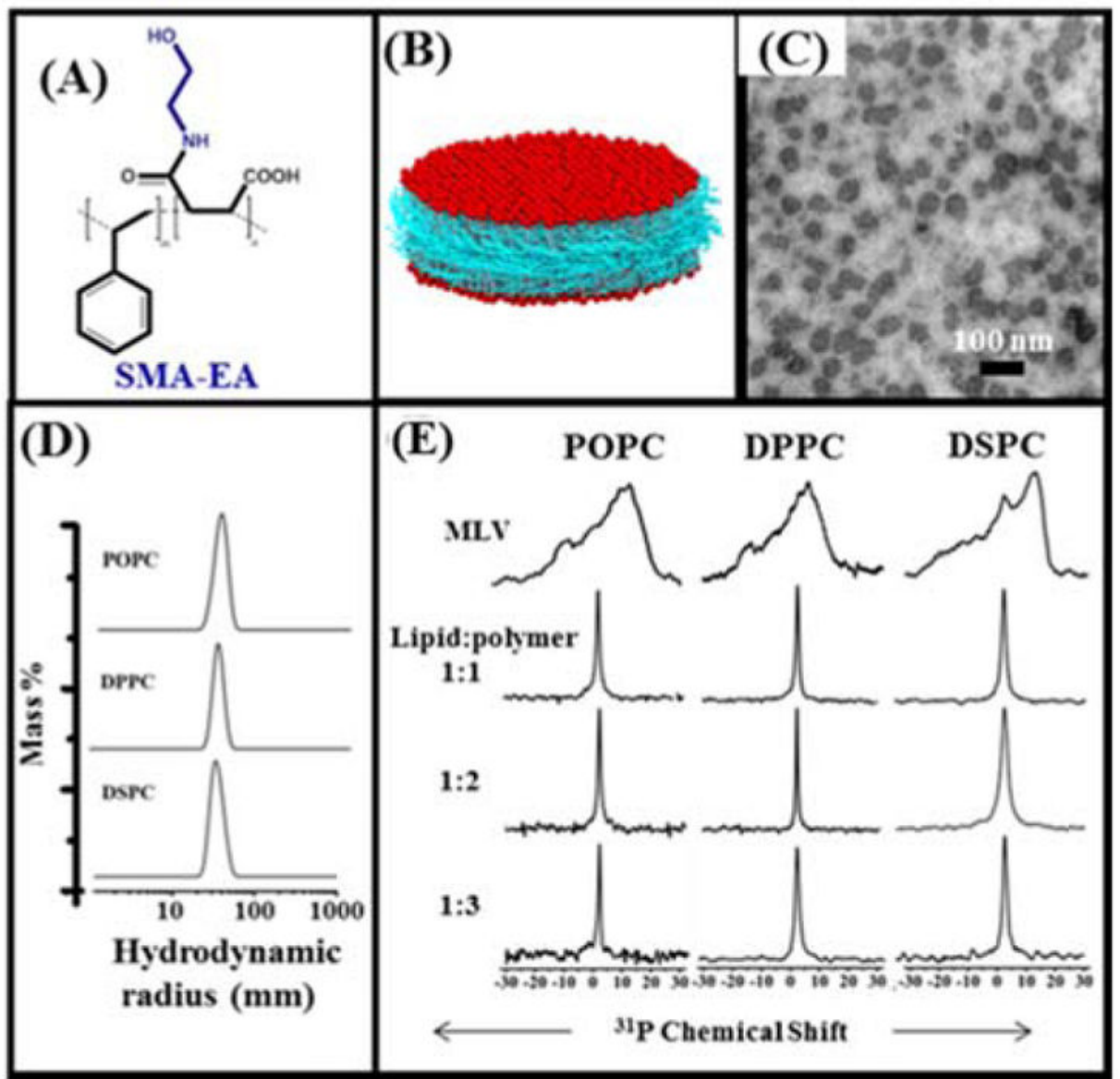

Figure 1.

(A) Structure of SMA-EA polymer, (B) Schematic showing a SMA-EA nanodisc containing a lipid bilayer, (C) TEM micrograph of DMPC macro-nanodisc with 1:1 (w/w) ratio of DMPC:SMA-EA, (D) DLS profiles of macro-nanodiscs of 1:1 lipid:polymer molar ratio (also see Figure $\mathrm{S} 1$ ), and (E) ${ }^{31} \mathrm{P}$ solid-state NMR spectra of MLVs and the isotropic nanodiscs formed with the addition of polymer as indicated by lipid:polymer (w/w). Solubilization of 7:3 POPC: POPG MLVs by SMA-EA to form nanodiscs revealed by ${ }^{31} \mathrm{P}$ NMR is shown in Figure S2. 


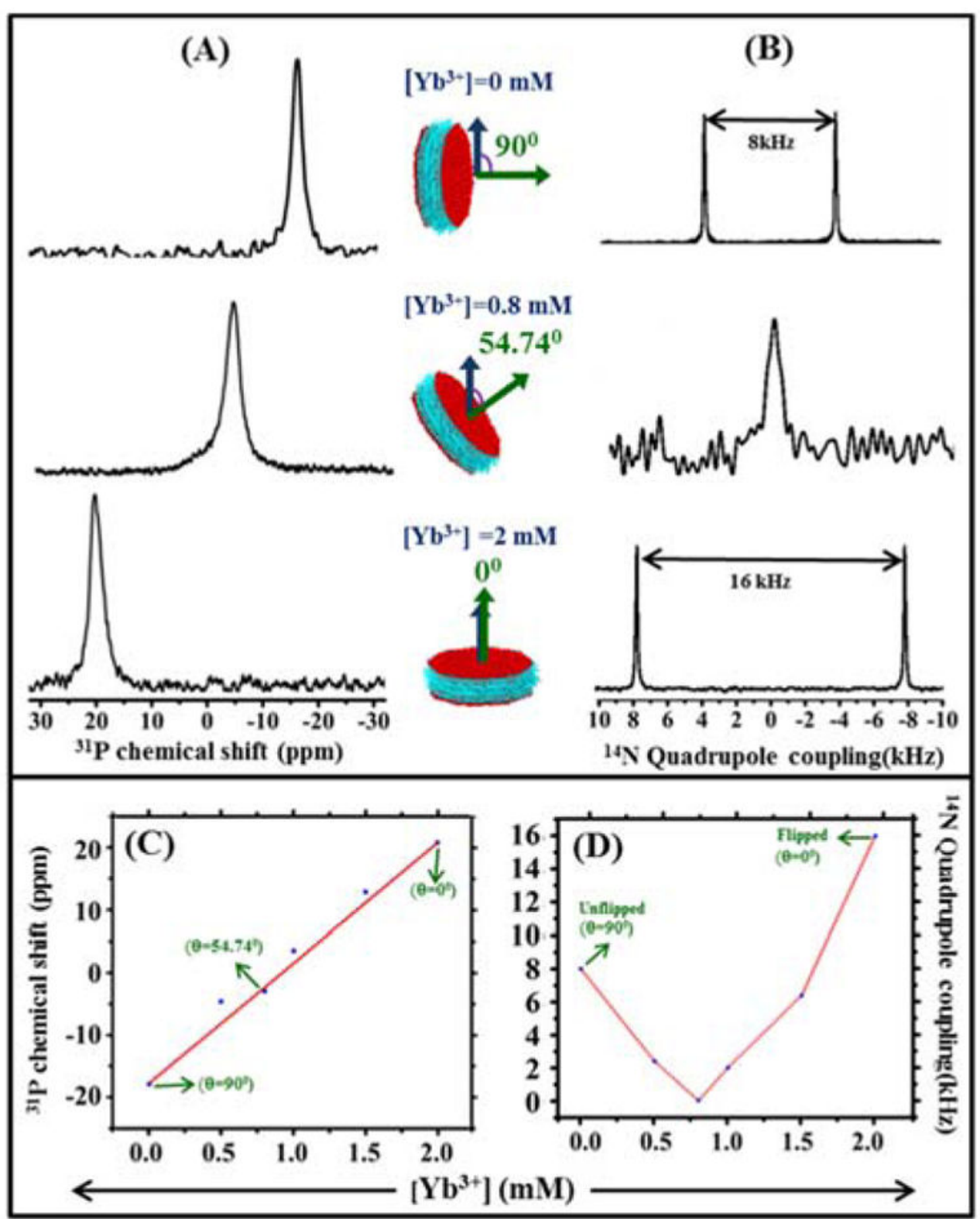

Figure 2.

Magnetic alignment of 1:1 DMPC:SMA-EA macro-nanodiscs in a fluid lamellar phase obtained at $35{ }^{\circ} \mathrm{C}$ with the addition of indicated amount of lanthanide salt $\left(\mathrm{YbCl}_{3}\right) .{ }^{31} \mathrm{P}(\mathrm{A})$ and ${ }^{14} \mathrm{~N}(\mathrm{C}) \mathrm{NMR}$ spectra. Plot of ${ }^{31} \mathrm{P}$ chemical shifts $(\mathrm{C})$ and ${ }^{14} \mathrm{~N}$ quadrupolar coupling (D) measured from the DMPC-SMA-EA macro-nanodiscs for different concentrations of $\mathrm{YbCl}_{3} \cdot{ }^{31} \mathrm{P}$ and ${ }^{14} \mathrm{~N}$ spectra of macro-nanodiscs for varying concentration of $\mathrm{YbCl}_{3}$ are shown in Figures S3 and S4. 


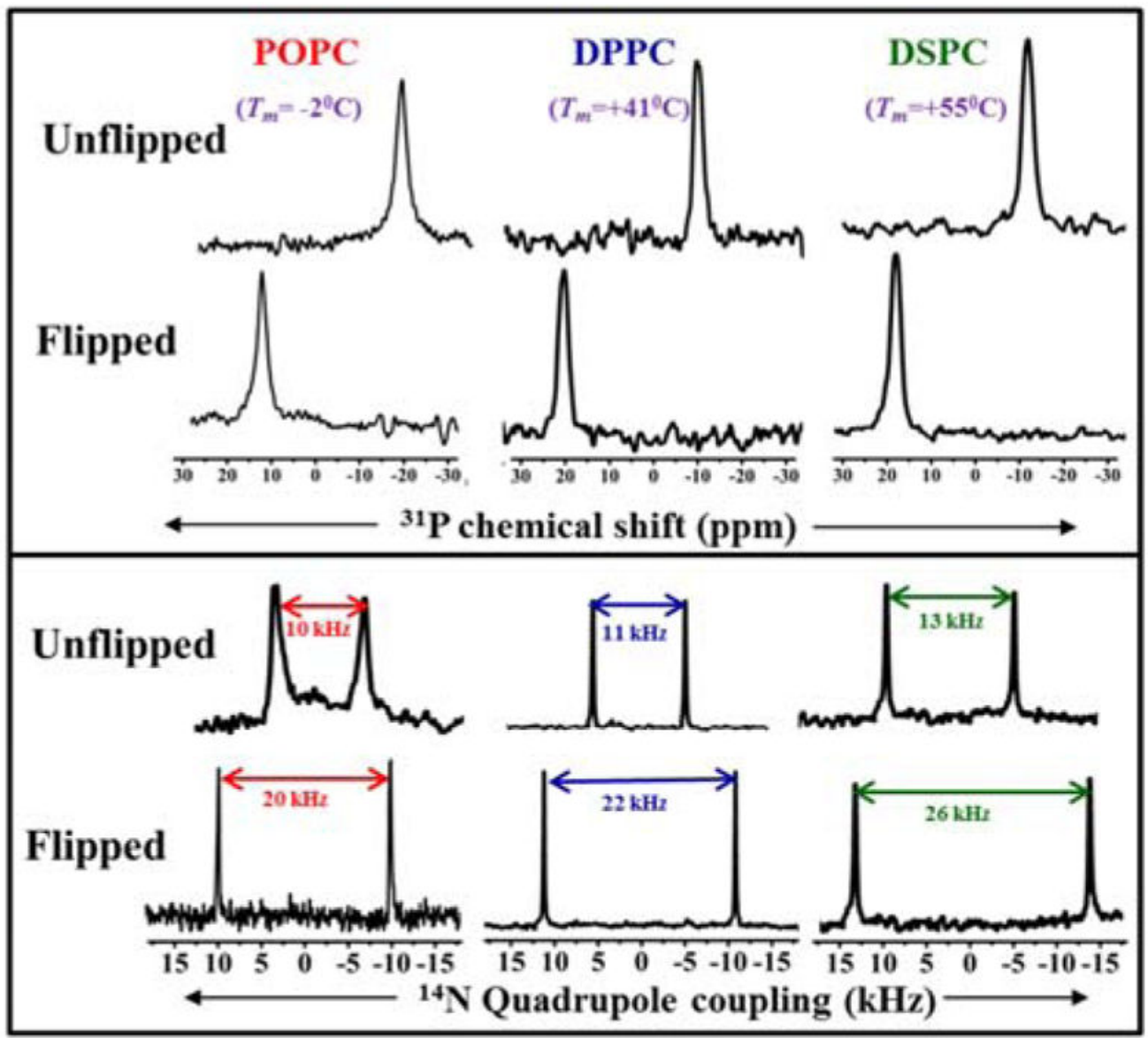

Figure 3.

${ }^{31} \mathrm{P}$ (top) and ${ }^{14} \mathrm{~N}$ (bottom) NMR spectra revealing the magnetic-alignment of SMA-EA polymer macro-nanodiscs composed of POPC, DPPC or DSPC. The gel to liquid crystalline phase transition temperatures for POPC, DPPC and DSPC are $-2,41$ and $55^{\circ} \mathrm{C}$, respectively. 


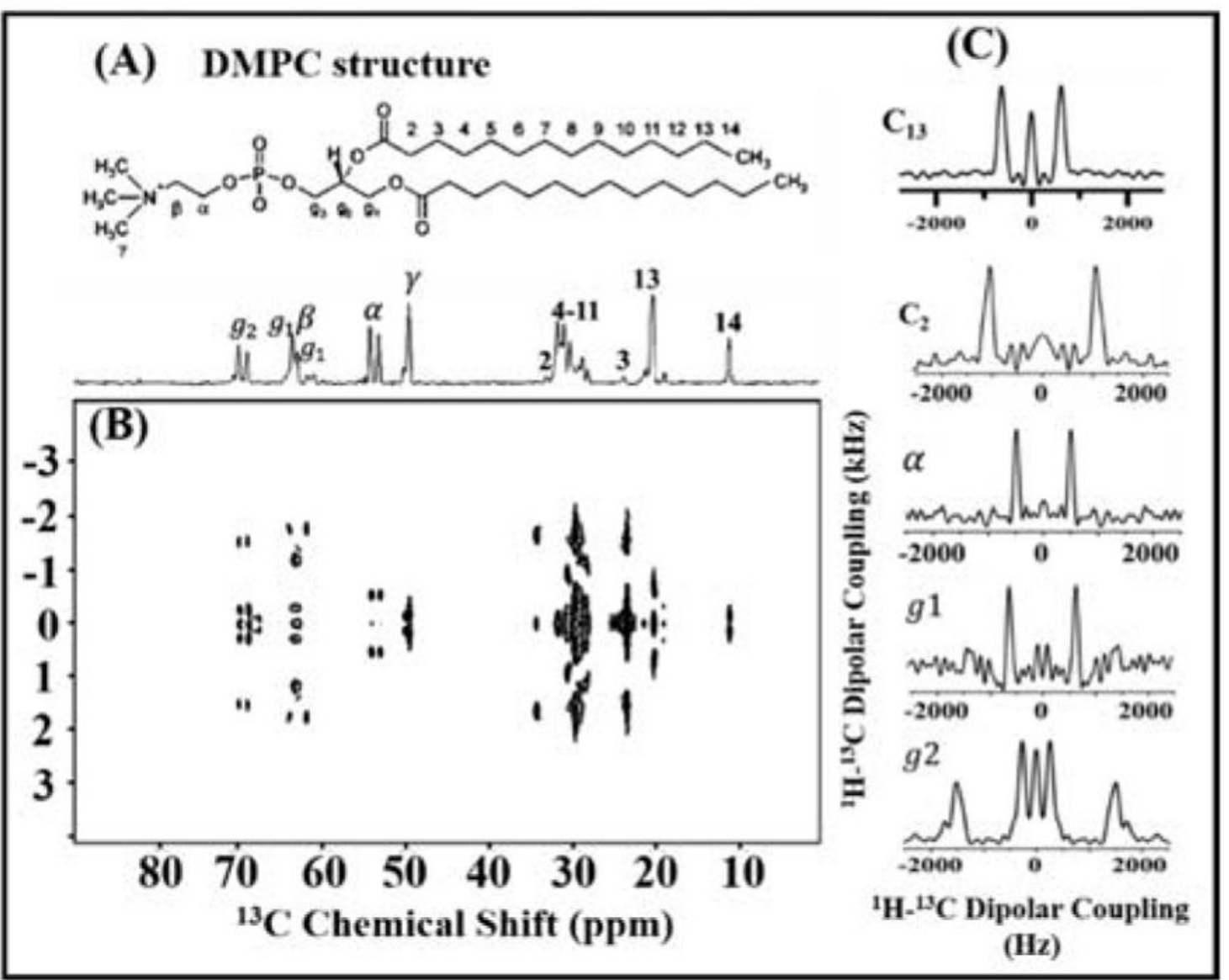

Figure 4.

Structure of DMPC (A), 2D ${ }^{1} \mathrm{H}^{13} \mathrm{C}$ PELF spectrum of 1:1 DMPC:SMA-EA macronanodiscs (B) recorded at $35{ }^{\circ} \mathrm{C}$, and ${ }^{1} \mathrm{H}_{-}{ }^{13} \mathrm{C}$ dipolar coupling spectral slices extracted for different carbons of DMPC (C) 2D PELF spectrum of 1:1 DPPC: SMA-EA macronanodiscs is given in Figure S5. 